Randomized Trial

\title{
Bilateral Spinal Decompression of Lumbar Central Stenosis with the Full-Endoscopic Interlaminar Versus Microsurgical Laminotomy Technique: A Prospective, Randomized, Controlled Study
}

Martin Komp, Dr. med. ${ }^{1}$, Patrick Hahn, Dr. med. ${ }^{1}$, Semih Oezdemir, Dr. med. ${ }^{1}$, Athanasios Giannakopoulos, Dr. med. ${ }^{1}$, Roderich Heikenfeld, Dr. med. ${ }^{3}$, Richard Kasch, Dr. med. ${ }^{2}$, Harry Merk, Prof. Dr. med. ${ }^{2}$ Georgios Godolias, Prof. Dr. med. ${ }^{3}$, and Sebastian Ruetten, Priv. Doz. Dr. med. habil'

From: ${ }^{1}$ Center for Spine Surgery and Pain Therapy, Center for Orthopaedics and Traumatology of the St. Elisabeth Group - Catholic Hospitals RheinRuhr, St. Anna Hospital Herne/ Marienhospital Herne University Hospital/ Marien Hospital Witten, Germany; ${ }^{2}$ Clinic for Orthopaedics and Orthopaedic Surgery, Ernst

Moritz Arndt University Greifswald, Greifswald, Germany; ${ }^{3}$ Center for Orthopaedics and Traumatology of the St. Elisabeth Group - Catholic Hospitals Rhein-Ruhr, St. Anna Hospital Herne/Marien Hospital Herne University Hospital/ Marien Hospital Witten, Germany

Address Correspondence: Martin Komp

Vice-Head Center for Spine Surgery and Pain Therapy

Center for Orthopaedics and Traumatology

St. Anna Hospital Herne Hospitalstrasse 19 44649 Herne Germany

E-mail: M.Komp@annahospital.de

Disclaimer: There was no external funding in the preparation of this manuscript.

Conflict of interest: Each author certifies that he or she, or a member of his or her immediate family, has no commercial association (i.e., consultancies, stock ownership, equity interest, patent/licensing arrangements, etc.) that might pose a conflict of interest in connection with the submitted manuscript.

Manuscript received: 07-31-2013 Revised manuscript received: 08-06-2014 Accepted for publication: 09-02-2014
Background: Extensive decompression with laminectomy, where appropriate, is often still described as the method of choice when operating on degenerative lumbar spinal stenosis. Nonetheless, tissue-sparing procedures are becoming more common. Endoscopic techniques have become the standard in many areas because of the surgical advantages they offer and the benefits for rehabilitation. One key issue when operating on the spine was the development of instruments to provide sufficient bone resection under continuous visual control. This was achieved by using endoscopes for operations carried out in cases of spinal canal stenosis.

Objective: This study of patients with degenerative lumbar central spinal stenosis compares the results of spinal decompression using the full-endoscopic interlaminar technique (FI) with a conventional microsurgical laminotomy technique (MI).

Study Design: Prospective, randomized, controlled study.

Settings: 135 patients with microsurgical or full-endoscopic decompression were followed up for 2 years. Alongside general and specific parameters, the following measuring instruments were also used for the investigation: Visual Analog Scale (VAS), German version of the North American Spine Society Instrument (NASS), Oswestry Low-Back-Pain-Disability Questionnaire (ODI).

Results: Postoperatively $72 \%$ of the patients no longer had leg pain or the pain was almost completely reduced and $21.2 \%$ experienced occasional pain. The clinical results were the same in both groups. The rate of complications and revisions was significantly reduced in the FI Group. The full-endoscopic techniques brought advantages in the following areas: operation, complications, traumatization, rehabilitation.

Limitations: Lack of placebo control group.

Conclusions: The recorded results demonstrate that the full-endoscopic interlaminar bilateral decompression adopting a unilateral approach provides an adequate and safe supplement and alternative to the conventional microsurgical bilateral laminotomy technique when the indication criteria are fulfilled. At the same time, it offers the advantages of a minimally invasive intervention.

Key words: Spinal stenosis, central stenosis, spinal decompression, endoscopic spinal decompression, minimally invasive spine surgery

Pain Physician 2015: 18: 61-70 


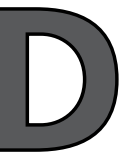

egenerative lumbar stenosis can be caused by bony, discal, capsular, or ligamentary structures. The compression may lead to the classic clinical symptoms of neurogenic claudication with radicular signs. Back pain is more likely to be attributable to degenerative secondary phenomena, such as segment instabilities or deformities. There are various hypotheses to explain the onset of pain associated with spinal stenosis and they include mechanical neural and vascular, inflammatory, as well as biomechanical reasons (1-4). There is no unequivocal correlation between the extent of stenosis observed in imaging procedures and the clinical symptoms (1-5).

In therapeutic terms, surgical intervention may be considered in cases of decompensation or intolerable persistence. In this respect, decompression, fusion, or a combination of the 2 procedures should be considered due to the possible leg and back symptoms. Numerous surgical procedures have been described, some of which are still the subject of controversial discussion (1-15). Overall, there appears to have been a trend over recent years involving a change from more aggressive to more selective techniques. The present tendency is to avoid fusion with predominantly leg symptoms, without any signs of segment instability and deformity and to use stability-preserving decompression techniques. However, there are no clear-cut definitions of these criteria. According to evidence-based medicine (EBM) criteria, it appears that decompression can now improve neurogenic claudication and neurological deficits. The required extent of decompression and the circumstances necessitating additional fusion remain unclear.

One operative consequence of surgery is scarring of the epidural space (16-19), which may become clinically symptomatic in $10 \%$ or more of cases (17-19) and this makes revision surgery more difficult. An analysis of study results in decompression revealed the occurrence of operation-induced destabilization due to the necessary resection of spinal canal structures (20-26). The point of access influences the stabilization and coordination system in the innervation area of the dorsal nerve roots for the spinal nerves (27-29). The use of microsurgical techniques has reduced tissue damage and its consequences (30-32).

The goal of new procedures must be to achieve results commensurate with current outcomes of standard techniques while minimizing traumatization and its negative long-term consequences. A focal point of technical developments in spinal surgery has been optimization of the intraoperative vision and light conditions, and this remains the case. With reference to this, endoscopic operations have become standard in various areas, such as arthroscopy or laparoscopy. Herniated discs and stenosis of the lumbar and cervical spine can now also be operated fully endoscopically using various accesses and techniques (33-39).

The goal of this prospective, randomized, controlled study was to compare the surgical results in degenerative lumbar central stenosis in full-endoscopic technique using an interlaminar approach with the results of a conventional microsurgical technique.

\section{Methods}

\section{Characteristics of Patients}

In the prospective, randomized, controlled study, we enrolled 160 patients with clinically symptomatic degenerative lumbar central stenosis who underwent surgical decompression. There were 91 women and 69 men whose ages ranged from 41 to 84 years (mean 62 years). The duration of symptoms ranged from 6 months to more than 5 years (mean 17 months). All patients had received a mean of 13 months of conservative treatment. The possible walking time averaged less than 20 minutes. The indication for surgery was defined according to present-day standards based on radicular pain symptoms or neurogenic claudication and existing neurological deficits $(40,41)$.

\section{Study Groups}

Eighty patients each underwent conventional microsurgical (MI) or full-endoscopic interlaminar (FI) decompression. Randomization was not blinded, since the patients may identify the operation procedure. After determination of the general indication for surgical decompression by experienced physicians who were not involved in the operation, randomized assignment was carried out by a non-physician study staff. The randomization was carried out as a block randomization. The secretary provided scheduling in a closed envelope containing details of the patients to be operated on. The randomization was balanced to the end of the study. All operations were performed by 2 surgeons with many years of experience in both techniques. The results of the study group (FI) were compared to those of the control intervention group (MI). The patients were informed preoperatively about the procedure which was to be carried out on them. The follow-up investigators were not informed of which surgical procedure had been carried out. Eleven interventions were 
performed at the L5-S1 level ( $4 \times \mathrm{MI}, 7 \times \mathrm{FI}), 80$ at L4-L5 $(42 \times \mathrm{MI}, 38 \times \mathrm{FI}), 55$ at L3-L4 $(25 \times \mathrm{MI}, 30 \times \mathrm{FI})$, and 14 at L2-L3 (9 $\times$ MI, $5 \times \mathrm{Fl})$.

\section{Inclusion Criteria}

The following inclusion criteria were applied: predominant leg symptoms, neurogenic claudication with or without paresis, back pain maximum 30/100 on the visual analogue scale (VAS), conservative therapy exhausted or no longer indicated due to the symptoms, monosegmental central stenosis caused by facet hypertrophy, hypertrophy of the ligamentum flavum, and disc protrusions or the combination of those. Exclusion criteria were predominant back pain, foraminal stenosis in the lower level, fresh soft disc herniations with bony stenosis, degenerative spondylolisthesis more than Meyerding Grade I, multidirectional rotation slide, scoliosis more than $20^{\circ}$, prior surgery in the same segment, and cauda equina syndrome. In summary, an attempt was made to define inclusion criteria which do not represent a clear indication for additional fusion, also taking clinical symptoms into account.

\section{Full-Endoscopic Instruments}

The working sheaths are inserted bluntly using a dilatator. They have an outer diameter of $10 \mathrm{~mm}$ and a beveled opening, which enable visual and working fields to be created in an area without clear anatomically preformed cavity. The scope has an outer diameter of $9.5 \mathrm{~mm}$ and is inserted through the working sheath. The scope contains an intraendoscopic, excentric working channel with a diameter of $5.7 \mathrm{~mm}$, the fiber optic system, a channel for continuous irrigation, and the rod lens system. The angle of view is $20^{\circ}$. Various instruments including drills up to $5.5 \mathrm{~mm}$ in diameter can be used (Fig. 1). All of the operating instruments and optical systems were products supplied by WOLF (Richard Wolf GmbH, Knittlingen, Germany).

\section{Operating Technique}

The conventional Ml operation was performed using the bilateral laminotomy technique. After a median skin incision of approximately $4 \mathrm{~cm}$ in length, the fascia was exposed, most of the musculature was bluntly prepared unilaterally, and a modified Caspar Retractor was inserted. After applying the retractor, the subsequent procedure was microscope-assisted using the familiar standardized technique. Decompression was carried out depending on the pathology by cranial and caudal laminotomy, partial facetectomy, and flavum resection.

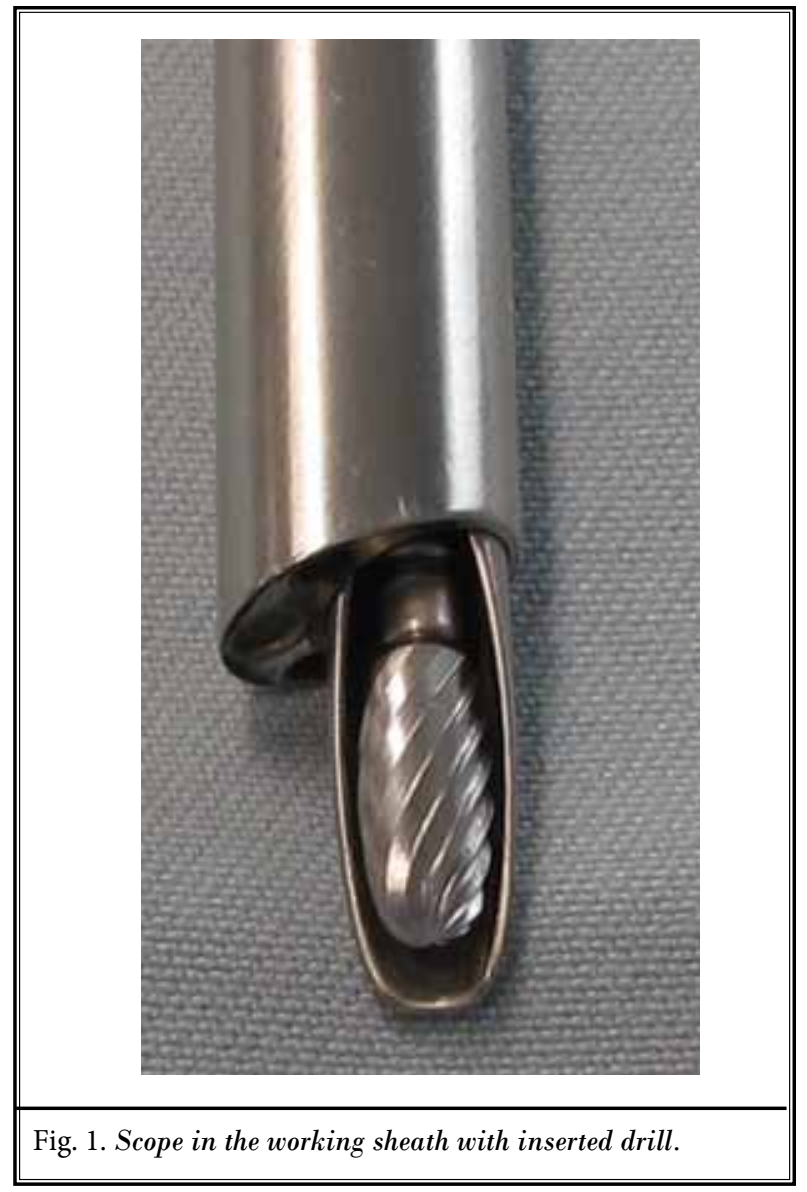

After transference of the retractor to the opposite side, decompression was performed analogously on the contralateral side.

The Fl operation was performed bilaterally via a unilateral access using an "undercutting technique." After making a paramedian skin incision approximately $9 \mathrm{~mm}$ long, blunt insertion of a dilatator toward the interlaminar window was performed. This was followed by insertion of the operation sheath over the dilatator with the beveled opening directed medially toward the ligamentum flavum. The procedure then was performed under visual control and constant irrigation. Depending on the pathology, first ipsilateral decompression was performed by means of cranial and caudal laminotomy, partial facetectomy, and resection of the flavum. The entry to the contralateral side was performed dorsal to the dura. The ligamentum flavum is initially left intact as far as possible as protection for the dura and bony decompression is performed again using cranial and caudal laminotomy and partial facetectomy. Subsequently, the ligamentum flavum is completely resected. The decompression is concluded 


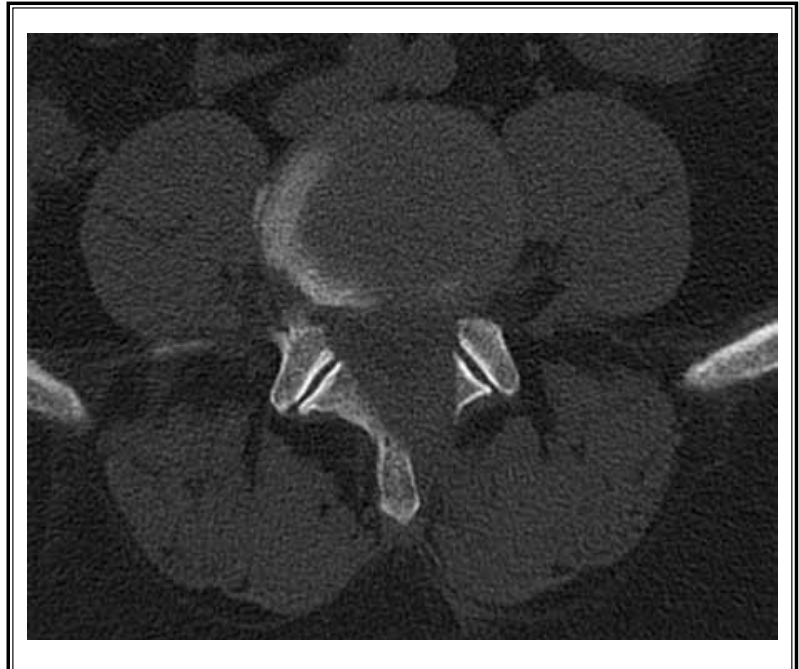

Fig. 2. Postoperative CT-scan after complete full-endoscopic bilateral decompression.

when the dura and spinal nerves are seen to be clearly decompressed on both sides (Fig. 2).

The operation was performed in all groups under general anesthesia and radiographic control with the patient in a supine position. Drainage was applied only in the MI Group. No opening of the annulus was created for performance of intradiscal nucleotomy. All patients were given a lumbar brace for 8 weeks.

\section{Follow-up}

Follow-up examinations were conducted on day 1 (160 patients) and at 3 months (153 patients), 6 months (148 patients), 12 months (144 patients), and 24 months (135 patients) after surgery. All patients received the appropriate questionnaire by mail 4 working days in advance. They came to the clinic in person for a followup examination. The examinations were performed by 2 doctors at the clinic who had not been involved in the operations. As well as general parameters, other information was obtained using the following instruments: a VAS for back and leg pain, the German version of the North American Spine Society Instrument (NASS) $(42,43)$, and the Oswestry Low-Back Pain Disability Questionnaire (ODI) (44). All patients underwent functional $x$-rays at the end of the follow-up period.

\section{Statistical Analysis}

The Wilcoxon rank-sum test and the Mann-Whitney $U$ Test were applied for comparing the preoperative and postoperative global results and for comparing the results in the $\mathrm{Ml}$ group versus the $\mathrm{Fl}$ group at various times. The McNemar Test was used to compare the characteristics of the groups. The descriptive assessments and analytical statistics were carried out with the SPSS program package in accordance with the group characteristics. A positive significance level was assumed at a probability of less than 0.05 .

\section{Results}

\section{Baseline Characteristics}

One hundred thirty-five $(84.4 \%)$ patients were included in the follow-up after 2 years $(64 \times \mathrm{MI}, 71 \mathrm{x}$ $\mathrm{Fl})$. The remaining cases were lost for the following reasons: one death unrelated to the operation (17 months postoperative), 3 patients moved away and left no forwarding address, and 21 patients did not respond to letters or telephone calls. The patient population was equal in the $\mathrm{MI}$ and $\mathrm{FI}$ groups. Overall, there were no differences in results between individual surgeons.

\section{Operative Technique}

The mean operating time in the Fl group was 42 minutes (33 to 64), and thus significantly shorter $(P<$ 0.05 ) than the time in the MI group at 64 minutes ( 43 to 93). The mean intraoperative and postoperative blood loss was $73 \mathrm{~mL}(20$ - 390) in the Ml group (measured by intraoperative suctioning and postoperative drainage); there was no measurable blood loss in the FI group. However, blood loss in the FI group cannot be precisely measured due to continuous irrigation. No drainage was required in the $\mathrm{Fl}$ group. Measurement of the lavage fluid inflow and outflow showed a maximum of 15 milliliters remaining in the patient. The operation in the Fl group was technically feasible in all patients. An intraoperative switch to a conventional procedure was not necessary in any patient. The patients in both groups were mobilized directly after the operation, depending on the effects of anesthesia.

\section{Perioperative Complications and Revisions}

The following complications occurred: 11 times transient postoperative dysesthesia $(7 \times \mathrm{MI}, 4 \times \mathrm{Fl}), 4$ times transient urinary retention ( $3 \times \mathrm{MI}, 1 \times \mathrm{FI})$, and 5 times dura injuries $(3 \times \mathrm{MI}=3.8 \%, 2 \times \mathrm{FI}=2.5 \%)$. These dura injuries were sutured and covered with a dural graft matrix in the MI group. In the FI group the lesion was covered with a dural graft matrix after finishing the operation and stopping the irrigation. There were 3 cases of increase in foot dorsiflexion paresis present before the operation $(2 \times \mathrm{MI}, 1 \times \mathrm{FI})$, one epidural hematoma requiring revision $(1 \times \mathrm{MI}), 3$ delayed wound healing ( 2 
$x \mathrm{MI}, 1 \times \mathrm{Fl})$, and 2 soft-tissue infections ( $2 \times \mathrm{MI})$. There were no other complications such as spondylodiscitis, cauda equina syndrome, or thrombosis. Apart from transient dysesthesia and transient urinary retention, the complication rate was $8.8 \%(\mathrm{MI}=12.5 \%, \mathrm{Fl}=5 \%)$ and was significantly higher in the Ml group $(P<0.05)$.

Four patients $(3 \%)$ required revision surgery due to persistent leg pain and/or increasing back pain $(2 \times \mathrm{MI}=$ $3.1 \%, 2 \times \mathrm{FI}=2.8 \%), 3$ of these additionally underwent fusion $(2 \times \mathrm{MI}, 1 \times \mathrm{FI})$. All revision operations were performed during the follow-up observation period, the earliest after 6 months. The differences in the revision rate between the 2 groups were not significant.

\section{Radiological Findings}

All patients were examined at the end of the follow-up period using functional x-rays (132 non-revised patients without fusion). Eighteen patients (13.6\%) showed an increase in disc degeneration at the operated level which had existed preoperatively $(8 \times \mathrm{Ml}=$ $12.9 \%, 10 \times \mathrm{FI}=14.3 \%$, not significant). Six patients $(4.5 \%)$ presented with an increased kyphosis angle in the operated segment $(4 \times \mathrm{Ml}, 3 \times \mathrm{Fl}$, not significant). The height of the intervertebral space decreased in 15 patients (11.4\%) $(7 \times \mathrm{Ml}, 8 \times \mathrm{Fl}$, not significant). There were 3 cases (2.3\%) $(2 \times \mathrm{Ml}, 1 \times \mathrm{Fl}$, not significant) of increased spondylolisthesis from grade I to grade II after surgery. Apart from these 3 patients, there was no increased instability in the functional examinations. There was no significant dependence between kyphosis, height of intervertebral space, radiological instability, and the clinical outcome.

\section{Clinical Outcome}

Excluding the patients revised by fusion, 132 patients remained after 2 years. Figs. 3 to 6 show VAS pain scores, ODI scores, and NASS scores. Overall, the measuring instruments demonstrate constant and significant $(P<0.001)$ improvement in leg pain and daily activities in both groups. Fig. 7 presents the complete depiction of the leg pain status after 2 years. Ninety-five patients $(72 \%)$ no longer had leg pain or the pain was almost completely eliminated $(42 \times \mathrm{MI}=67.7 \%, 53 \times \mathrm{FI}$ $=75.7 \%), 28(21.2 \%)$ had pain occasionally or the pain was greatly reduced $(16 \times \mathrm{MI}=25.8 \%, 12 \times \mathrm{FI}=17.2 \%)$, and $9(6.8 \%)$ experienced no essential improvement (4 $\mathrm{x} \mathrm{MI}=6.5 \%, 5 \times \mathrm{FI}=7.1 \%$ ). Walking time improved from an average of less than 20 minutes to more than 50 minutes. In general, there was slight deterioration in the follow-up period between the first and second
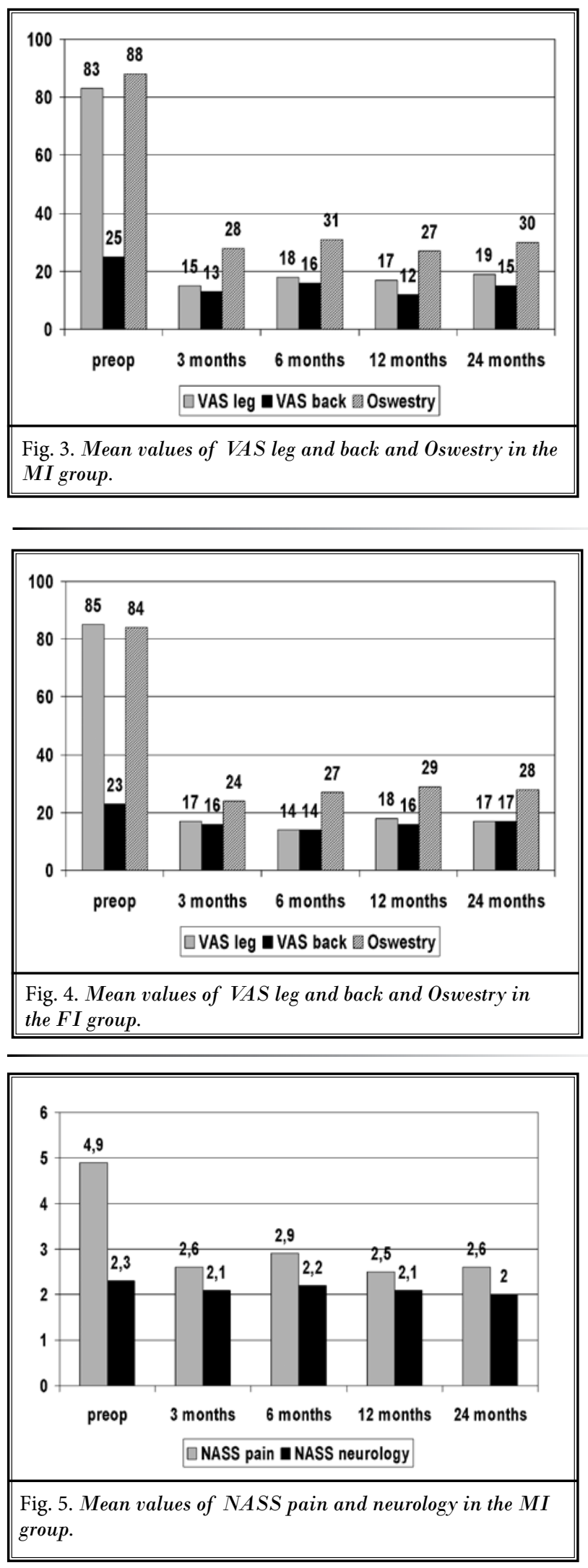


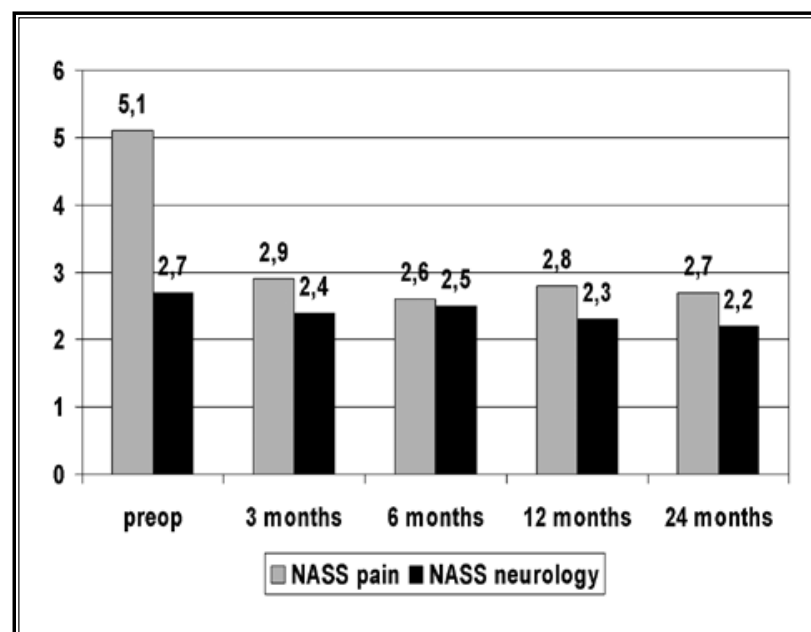

Fig. 6. Mean values of NASS pain and neurology in the FI group.
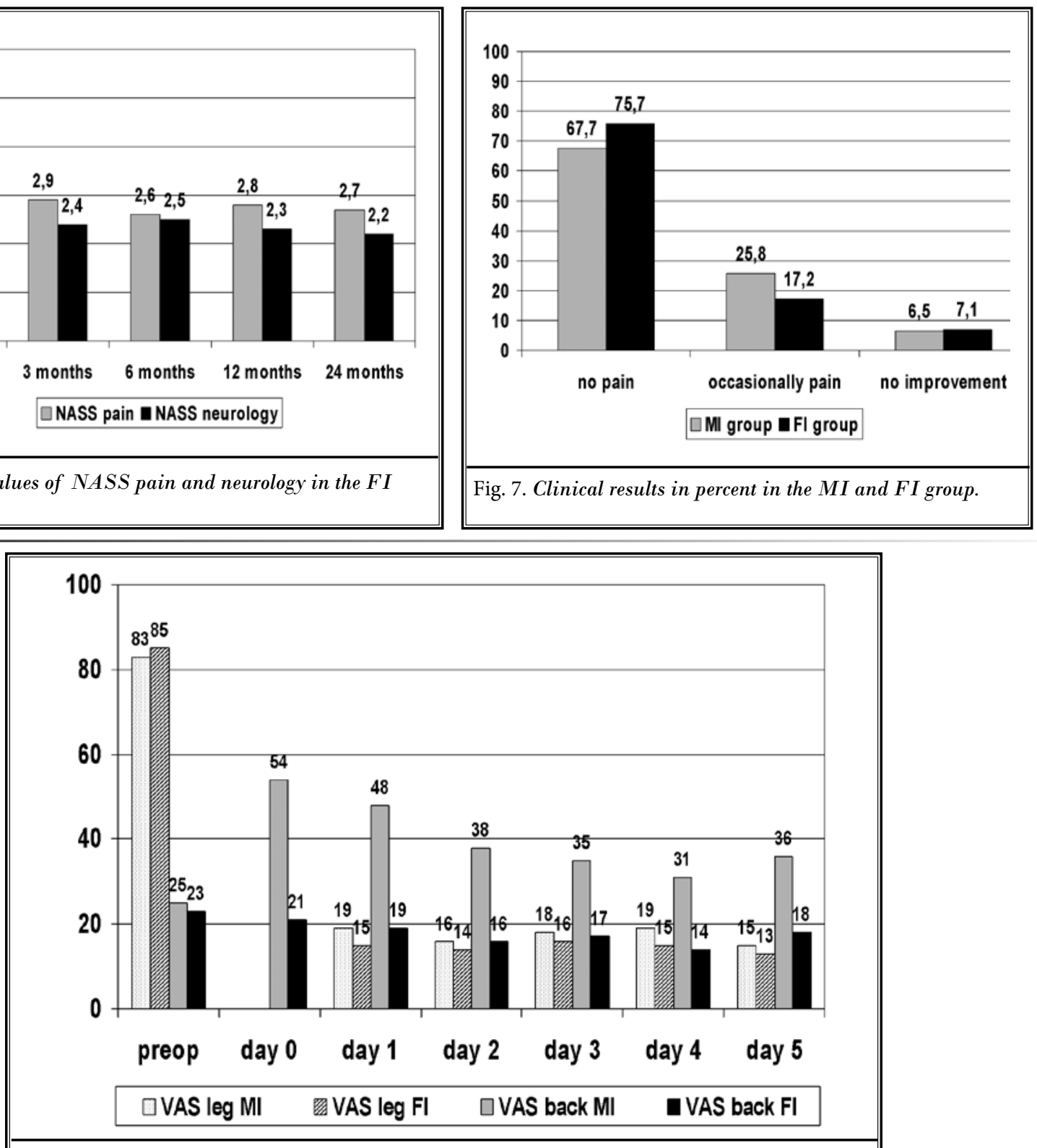

Fig. 8. Postoperative leg and back pain in the MI and FI group. years, but this was not significant. The differences in the clinical results between the groups were not significant. Nine patients suffered increasing back pain $(7 \mathrm{x}$ $\mathrm{MI}, 2 \times \mathrm{FI}[P<0.01])$.

Overall, 4 patients $(3 \%)(2 \times \mathrm{MI}, 1 \times \mathrm{FI})$ underwent revision with decompression (1) and with additional fusion (3). Overall, 13 patients $(9.6 \%)$ had a poor result in terms of no leg pain reduction (9 patients) or had to undergo conventional revision surgery later for persistent pain (4 patients). One hundred nineteen (88.1\%) patients reported subjective satisfaction and would undergo the operation again $(56 \times \mathrm{MI}=87.5 \%, 63 \times \mathrm{FI}$ $=88.7 \%)$. Neurological deficits were significantly $(P<$ 0.001 ) reduced when the patient's history of weakness was less than 6 weeks. Overall, the clinical results were significantly better $(P<0.01)$ if the general anamnesis time was less than 1.5 years.

Postoperative pain was determined over 5 days using the VAS (Fig. 8). The use of postoperative pain medication was defined by need. Opioids WHO class 
III were available for the first postoperative day, metamizole and ibuprofen or paracetamol were used starting on the second postoperative day. Postoperative pain and pain medication were significantly reduced in the $\mathrm{FI}$ group $(P<0.01)$. On the second postoperative day, $48 \%$ of the patients in the Ml group and $11 \%$ of the patients in the Fl group requested analgesics. The maximum time in hospital was 8 days in the Ml group and 3 days in the FI group.

\section{Discussion}

Conventional decompression of degenerative lumbar stenosis with laminectomy or extensive resection has been described as the technique of choice and this is frequently still the case $(6,7,11,14,45)$. Scarring of the epidural space can be problematic $(16-19,28,46)$. It may become clinically symptomatic (17-19), make revisions more difficult, and may lead to "tethering" of the cauda equina due to the postoperative connection between the epidural space and paravertebral musculature (14,47-49). The resection of structures preserving stability may promote operation-induced segmental instability (20-26). The route of access in the innervation area of the dorsal branch of the spinal nerves may exert a negative impact on the stabilization and coordination system (27-29). Resection of joint and soft-tissue structures in the lateral and ventral area is also required for decompression of degenerative stenosis and this occurs particularly often. This is possible with more tissue-sparing techniques which are being increasingly applied $(8,12,14,15,50-53)$. They are also used for other indications.

Technical advances have been made in the operation of disc herniations in the cervical and lumbar spine which now permit a full-endoscopic procedure under continuous irrigation. This can provide the advantages of a truly minimally invasive procedure $(33,35-39)$. One key issue was the possibility of adequate bone resection under continuous visual control (33-38). This also enabled the technique to be used in the operation of spinal canal stenosis (34).

After 2 years, the clinical results with the full-endoscopic technique were equal to those obtained with the microsurgical technique and are in accordance with data reported in the literature $(6-8,12,14,15,45,48,50-56)$. This has been taken as the minimum baseline for new techniques. A significant improvement was achieved in the $\mathrm{Ml}$ and $\mathrm{Fl}$ groups after 2 years without significant differences. A slow deterioration in surgical results over time has been described $(55,57-60)$. The number of patients who reported increasing back pain during the follow-up period was higher in the MI group. When resection of spinal canal structures is avoided or the extent of resection is reduced, a minimally traumatic procedure appears capable of reducing operation-induced consequences $(19,25,45,61-66)$. Postoperative pain and pain medication were significantly reduced in the $\mathrm{FI}$ group. The results of these parameters in a literature comparison also favor the FI group (67-71). The rate of complications of $12.5 \%$ in the Ml group was within the range found in the literature, but it was significantly reduced in the $\mathrm{FI}$ group at 5\% $(6-8,12,14,15,45,48,51$ $53,55,72,73)$. The maximum duration of hospitalization was shortened as a result of using the full-endoscopic technique.

The mean operation time in the Fl group of $42 \mathrm{~min}$ utes was significantly shorter than in the MI group with a mean time of 64 minutes. No blood loss was observed in the $\mathrm{Fl}$ group and no drainage was required. The necessity of resection stabilizing structures was reduced in the Fl group. The reduction in operating time, traumatization, and operation-related sequelae in the FI group is also found in a comparison of the literature relating to discectomies $(34-37,69,71,74)$.

To date, it remains difficult to identify clearly defined parameters that are generally applicable according to EBM criteria which require fusion in addition to decompression. At present, the tendency with predominant leg symptoms, without signs of segment instability and deformity, is to avoid fusion when stability-preserving decompression techniques are used. In the study performed, no significant parameter relating to operation-induced instability had occurred after 2 years. Overall, there was no significant dependence between kyphosis, height of intervertebral space, radiological instability, and the clinical outcome. This study was based on the indication monosegmental central stenosis with predominant leg pain and it appears to indicate that additional fusion can be eliminated with a stability-preserving surgical technique provided there are no clear-cut signs of instability or axis deviations preoperatively.

The goal of surgical treatment of lumbar stenosis is sufficient decompression with minimization of operation-induced traumatization and related consecutive sequelae. Overall, no disadvantages were found in this study when using the FI technique. At the same time, the operative technique offers advantages and provides a minimally invasive procedure around the access and the spinal canal structures. In our department, the 
microscope-assisted, bilateral laminotomy technique was the standard procedure for the indications cited. The full-endoscopic technique was therefore compared to that procedure.

The full-endoscopic bilateral operation with unilateral approach for lumbar degenerative central stenosis is an adequate and safe supplementation and alternative. This technique has become the standard procedure in our department for the cited indication. This is a minimally invasive surgical technique for spinal decompression, which has long been a validated and established standard procedure. In our opinion, the following advantages are offered: ease of operation for the surgeon due to excellent visualization, good illu- mination, and expanded field of vision with $25^{\circ}$ scope; cost-effective procedure due to short operating time, rapid rehabilitation, and low postoperative costs of care; reduced anatomical trauma; and monitor image as training basis for assistants. The following must be considered disadvantages: limited option of extending the approach in the event of unforeseen problems and difficult learning curve.

\section{Conclusions}

In conclusion, it is important to emphasize that the necessity for laminectomies, especially for additional fusions, may still remain outside the indications described here.

\section{References}

1. Benini A. Lumbar spinal stenosis. An overview 50 years following initial description. Orthopaede 1993; 6:461-472.

2. Cinotti G, Postachini F, Fassari F, Urso S. Predisposing factors in degenerative spondylolisthesis. A radiographic and CT study. International Orthopaedics 1997; 21:337-342.

3. Rydevik B. Neurophysiology of cauda equina compression. Acta Orthop Scand 1993; 64:52-55.

4. Takahashi K, Miyazakit T, Takino T, Tomita K. Epidural pressure measurement. Relationship between epidural pressure and posture in patients with lumbar spinal stenosis. Spine 1995; 20:650-653.

5. Torgerson WR, Dotter WE. Comparative roentgenographic study of the asymptomatic and symptomatic lumbar spine. J Bone J Surg 1972; 58:850-853.

6. Caputy AJ, Luessenhop AJ. Long-term evaluation of decompressive surgery for degenerative lumbar stenosis. ] Neurosurg 1992; 7:669-676.

7. Fox MW, Onofrio BM, Hanssen AD. Clinical outcomes and radiological instability following decompressive lumbar laminectomy for degenerative spinal stenosis: A comparison of patients undergoing concomitant arthrodesis versus decompression alone. J Neurosurg 1996; 85:793-802.

8. Getty CJM, Johnson JR, Kirwan E, O'Sullivan MF. Partial undercutting facetectomy for bony entrapment of the lumbar nerve root. J Bone ] Surg Br 1981;
63:330-335

9. Herkowitz HN. Degenerative lumbar spondylolisthesis with spinal stenosis. J Bone J Surg 1991; 73:802-808.

10. Herno A, Airaksinen O, Saari T. Longterm results of surgical treatment of lumbar stenosis. Spine 1993; 17:1471-1474.

11. Katz JN, Lipson SJ, Lew RA, Grobler LJ, Weinstein JN, Brick GW, Fossel AH, Liang $\mathrm{MH}$. Lumbar laminectomy alone or with instrumented or noninstrumented arthrodesis in degenerative lumbar spinal stenosis. Spine 1997; 22:1123-1131.

12. Mayer HM, List J, Korge A, Wiechert K. Microsurgery of acquired degenerative lumbar spinal stenosis. Bilateral over-the-top decompression through unilateral approach. Orthopaede 2003; 32:889-895.

13. Quint U, Wilke HJ, Loer F, Claes LE. Functional sequelae of surgical decompression of the lumbar spine - a biomechanical study in vitro. Z Orthop 1998; 136:350-357.

14. Ragab AA, Fye MA, Bohlmann HH. Surgery of the lumbar spine for spinal stenosis in 118 patients 70 years of age or older. Spine 2003; 28:348-353.

15. Sanderson PL, Getty CJM. Long-term results of partial undercutting facetectomy for lumbar lateral recess stenosis. Spine 1996; 21:1352-1356.

16. Annerzt $M$, Jonsson $B$, Stromqvist $B$, Holtas S. No relationship between epidural fibrosis and sciatica in the lumbar postdiscectomy syndrome. A study with contrast-enhanced magnetic resonance imaging in symptomatic and asymptomatic patients. Spine 1995; 20:449-453.

17. Fritsch EW, Heisel J, Rupp S. The failed back surgery syndrome: Reasons, intraoperative findings and long term results: a report of 182 operative treatments. Spine 1996; 21:626-633.

18. Kraemer J. Intervertebral Disk Diseases. Thieme, Stuttgart, 1990.

19. Schoegg| A, Maier H, Saringer W, Reddy $M$, Matula C. Outcome after chronic sciatica as the only reason for lumbar microdiscectomy. J Spinal Disord Tech 2002; 15:415-419.

20. Abumi K, Panjabi MM, Kramer KM, Duranceau J, Oxland T, Criso JJ. Biomechanical evaluation of lumbar spinal stability after graded facetectomies. Spine 1990; 15:1142-1147.

21. Haher TR, O'Brien M, Dryer JW, Nucci R, Zipnick R, Leone DJ. The role of the lumbar facet joints in spinal stability. Identification of alternative paths of loading. Spine 1994; 19:2667-2670.

22. Hopp E, Tsou PM. Postdecompression lumbar instability. Clin Orthop 1988; 227:143-151.

23. Kaigle AM, Holm SH, Hansson TH. Experimental instability in the lumbar spine. Spine 1995; 20:421-430.

24. Kato Y, Panjabi MM, Nibu K. Biomechanical study of lumbar spinal stability after osteoplastic laminectomy. J Spinal Disord 1998; 11:146-150.

25. Kotilainen E, Valtonen S. Clinical in- 
stability of the lumbar spine after microdiscectomy. Acta Neurochir 1993; 125:120-126.

26. Sharma M, Langrana NA, Rodrigues J. Role of ligaments and facets in lumbar spinal stability. Spine 1995; 20:887-900.

27. Cooper R, Mitchell W, Illingworth K, Forbes WS, Gillespie JE, Jayson MI. The role of epidural fibrosis and defective fibrinolysis in the persistence of postlaminectomy back pain. Spine 1991; 16:1044-1048.

28. Lewis PJ, Weir BKA, Broad RW, Grace MG. Long-term prospective study of lumbosacral discectomy. J Neurosurg 1987; 67:49-54.

29. Waddell G, Reilly S, Torsney B, Allan DB, Morris EW, Di Paola MP. Assessment of the outcome of low back surgery. J Bone Jt Surg Br 1988; 70:723-727.

30. Parke $W W$. The significance of venous return in ischemic radiculopathy and myelopathy. Orhop Clin North Am 1991; 22:213-220.

31. Schick U, Doehnert J, Richter A, Konig A, Vitzkun HE. Microendoscopic lumbar discectomy versus open surgery: An intraoperative EMG study. Eur Spine ] 2002; 11:20-26.

32. Weber BR, Grob D, Dvorak J, Muntener M. Posterior surgical approach to the lumbar spine and its effect on the multifidus muscle. Spine 1997; 22:1765-1772.

33. Ruetten S, Komp M, Merk H, Godolias G. Full-endoscopic anterior decompression versus conventional anterior decompression and fusion in cervical disc herniations. Int Orthop 2008; 33:1677. DOI 10.1007/s00264-008-0684-y

34. Ruetten S, Komp M, Merk H, Godolias G. Surgical treatment for lumbar lateral recess stenosis with the full-endoscopic interlaminar and transforaminal approach versus conventional microsurgical technique: A prospective, randomized, controlled study. J Neurosurg Spine 2008; 10:5,476-485.

35. Ruetten S, Komp M, Merk H, Godolias G. Recurrent lumbar disc herniation following conventional discectomy: A prospective, randomized study comparing full-endoscopic interlaminar and transforaminal versus microsurgical revision. J Spinal Disord Tech 2009; 22:2,122-129.

36. Ruetten S, Komp M, Merk H, Godolias G. Full-endoscopic cervical posterior foraminotomy for the operation of lateral disc herniations using $5.9-\mathrm{mm}$ endoscopes: A prospective, randomized, controlled study. Spine 2008; 33:940-948.

37. Ruetten S, Komp M, Merk H, Godolias
G. Full-endoscopic interlaminar and transforaminal lumbar discectomy versus conventional microsurgical technique: A prospective, randomized, controlled study. Spine 2008; 33:931-939.

38. Ruetten S, Komp M, Merk H, Godolias G. Use of newly developed instruments and endoscopes: Full-endoscopic resection of lumbar disc herniations via the interlaminar and lateral transforaminal approach. J Neurosurg Spine 2007; 6:521-530.

39. Ruetten S, Komp M, Godolias G. An extreme lateral access for the surgery of lumbar disc herniations inside the spinal canal using the full-endoscopic uniportal transforaminal approach. - Technique and prospective results of $463 \mathrm{pa}-$ tients. Spine 2005; 30:2570-2578.

40. Andersson GBJ, Brown MD, Dvorak J, Herzog RJ, Kambin P, Malter A, McCullough JA, Saal JA, Spratt KF, Weinstein JN. Consensus summary on the diagnosis and treatment of lumbar disc herniation. Spine 1996; 21:75-78.

41. McCulloch JA. Focus issue on lumbar disc herniation: Macro- and microdiscectomy. Spine 1996; 21:45-56.

42. Daltroy LH, Cats-Baril WL, Katz JN, Fossel $\mathrm{AH}$, Liang $\mathrm{MH}$. The North American Spine Society (NASS) Lumbar Spine Outcome Instrument: Reliability and validity tests. Spine 1996; 21:741-749.

43. Pose B, Sangha O, Peters A, Wildner M. Validation of the North American Spine Society Instrument for assessment of health status in patients with chronic backache. Z Orthop 1999; 137:437-441.

44. Fairbank JCT, Couper J, Davies JB, O`Brien JP. The Oswestry low back pain questionnaire. Physiotherapy 1980; 66:271-273.

45. Johnsson KE, Redlund-Johnell I, Uden A, Willner S. Preoperative and postoperative instability in lumbar spinal stenosis. Spine 1989; 14:591-593.

46. Ruetten S, Meyer O, Godolias G. Epiduroscopic diagnosis and treatment of epidural adhesions at chronic back pain syndrome of patients with previous surgical treatment: First results of 26 interventions. Z Orthop 2002; 140:171-175.

47. Katz JN, Lipson SJ, Larson MG, McInnes JM, Fossel AH, Liang MH. The outcome of decompressive laminectomy for degenerative lumbar stenosis. J Bone ] Surg Am 1991; 73:809-816.

48. LaRocca H, MacNab I. The laminectomy membrane. Studies in its evaluation, characteristics, effects and prophylaxis in dogs. J Bone J Surg Br 1974; 56:545-550.
49. Markwalder TM. Surgical management of neurogenic claudication in 100 patients with lumbar spinal stenosis due to degenerative spondylolisthesis. Acta Neurochir 1993; 120:136-142.

50. Frank EH, Hsu FP. An endoscopic dural retractor for spinal stenosis surgery. Minim Invasive Neurosurg 2002; 45:136-138.

51. Guiot BH, Khoo LT, Fessler RG. A minimally invasive technique for decompression of the lumbar spine. Spine 2002; 27:432-438.

52. Khoo LT, Fessler RG. Microendoscopic decompressive laminotomy for the treatment of lumbar stenosis. Neurosurgery 2002; 51:146-154.

53. Young S, Veerapen R, O'Laoire SA. Relief of lumbar canal stenosis using multilevel subarticular fenestration as an alternative to wide laminectomy: A preliminary report. Neurosurgery 1998; 23:628-633.

54. Ashraf AR, Mark AF, Henry HB. Surgery of the lumbar spine for spinal stenosis in 118 patients 70 years of age or older. Spine 2003; 28:348-535.

55. Katz JN, Lipson SJ, Chang LC, Levine SA, Fossel AH, Liang MH. Seven- to 10-year outcome of decompressive surgery for degenerative lumbar spinal stenosis. Spine 1996; 21:92-98.

56. Yamashita K, Ohzono K, Hiroshima K. Five-year outcomes of surgical treatment for degenerative lumbar spinal stenosis. Spine 2006; 31:1484-1490.

57. Airaksinen $\mathrm{O}$, Herno $\mathrm{A}$, Turunen $\mathrm{V}$, Saari T, Suomlainen O. Surgical outcome of 438 patients treated surgically for lumbar spinal stenosis. Spine 1997; 22:2278-2282.

58. Atlas SJ, Keller RB, Robson D, Deyo RA, Singer DE, Keller RB. Surgical and nonsurgical management of lumbar spinal stenosis: Four-year outcomes from the Maine Lumbar Spine Study. Spine 2000; 25:556-562.

59. Atlas SJ, Keller RB, Wu YA, Deyo RA, Singer DE. Long-term outcomes of surgical and nonsurgical management of lumbar spinal stenosis: 8 to 10 year results from the Maine Lumbar Spine Study. Spine 2005; 30:936-943.

6o. Cornefjord M, Byroed G, Brisby $\mathrm{H}$, Rydevik B. A long-term (4- to 12-year) follow-up study of surgical treatment of lumbar spinal stenosis. Eur Spine ] 2000; 9:563-570.

61. Ebara S, Harada T, Hosono N, Yonenobu K, Hiroshima K, Ono K. Intraoperative measurement of lumbar spinal instabil- 
ity. Spine 1992; 17:44-50.

62. Goel VK, Nishiyama K, Weinstein JN, Lin YK. Mechanical properties of lumbar spinal motion segments as affected by partial disc removal. Spine 1986; 11:1008-1012.

63. lida Y, Kataoka O, Sho T, Sumi M, Hirose T, Bessko Y, Kobayashi D. Postoperative lumbar spinal instability occurring or progressing secondary to laminectomy. Spine 1990; 15:1186-1189.

64. Kambin P, Cohen L, Brooks ML, Schaffer JL. Development of degenerative spondylosis of the lumbar spine after partial discectomy: Comparison of laminotomy, discectomy and posterolateral discectomy. Spine 1994; 20:599-507.

65. Natarajan RN, Andersson GB, Padwardhan AG, Andriacchi TP. Study on effect of graded facetectomy on change in lumbar motion segment torsional flexibility using three-dimensional continuum contact representation for facet joints. J Biomech Eng 1999; 121:215-221.

66. Zander T, Rohlmann A, Kloeckner C,
Bergmann G. Influence of graded facetectomy and laminectomy on spinal biomechanics. Eur Spine ] 2003; 12:427-434.

67. Caspar W, Campbell B, Barbier DD, Kretschmmer R, Gotfried Y. The Caspar microsurgical discectomy and comparison with a conventional standard lumbar disc procedure. Neurosurgery 1991; 28:78-87.

68. Mochida J, Nishimura K, Nomura T, Tok $E$, Chiba M. The importance of preserving disc structure in surgical approaches to lumbar disc herniation. Spine 1996; 21:1556-1564.

69. Rantanen J, Hurme M, Falck B, Alaranta $\mathrm{H}$, Nykvist F, Lekto M. The lumbar multifidus muscle five years after surgery for a lumbar intervertebral disc herniation. Spine 1993; 18:568-574.

70. Ross JS, Robertson JT, Frederickson RC, Petrie JL, Obuchowski N, Modic MT. Association between peridural scar and recurrent radicular pain after lumbar discectomy: Magnetic resonance evaluation. Neurosurgery 1996; 38:861-863.
71. Stolke D, Sollmann WP, Seifert V. Intra- and postoperative complications in lumbar disc surgery. Spine 1989; 14:56-59.

72. Malmivaara A, Slaetis $P$, Helioevaara $M$, Sainio $P$, Kinnunen $H$, Kankare J, Dalin-Hirvonen N, Seitsalo S, Herno A, Kortekangas P, Niinimaeki T, Roenty $\mathrm{H}$, Tallroth K, Turunen V, Knekt P, Haerkaenen $T$, Hurri $H$. Surgical or nonoperative treatment for lumbar spinal stenosis? A randomized controlled trial. Spine 2007; 32:1-8.

73. Podichetty VK, Spears J, Isaacs RE, Booher J, Biscup RS. Complications associated with minimally invasive decompression for lumbar spinal stenosis. J Spinal Disord Tech 2006; 19:161-166.

74. Caspar W. A new surgical procedure for lumbar disc herniation causing less tissue damaging through a microsurgical approach. In: Wuellenweber R, Brock M (eds). Advances in Neurosurgery. Springer Berlin Heidelberg pp. 74-77. 